\title{
Cerebellar hemorrhage after spine fixation misdiagnosed as a complication of narcotics use
} -A case report-

\author{
Ki-Hwan Yang, Jeong Uk Han, Jong-Kwon Jung, Doo Ik Lee, Sung-Il Hwang, and Hyun Kyoung Lim \\ Department of Anesthesiology and Pain Medicine, Inha University Hospital, Inha University College of Medicine, Incheon, Korea
}

Cerebellar hemorrhage occurs mainly due to hypertension. Postoperative cerebellar hemorrhage is known to be associated frequently with frontotemporal craniotomy, but quite rare with spine operation. A 56-year-old female received spinal fixation due to continuous leg tingling sensation for since two years ago. Twenty-one hours after operation, she was disoriented and unresponsive to voice. Performed computed tomography showed both cerebellar hemorrhage. An emergency decompressive craniotomy was carried out to remove the hematoma. On the basis of this case, we reported this complications and reviewed related literature. (Korean J Anesthesiol 2011; 60: 54-56)

Key Words: Cerebellar hemorrhage, Cerebrospinal fluid pressure, Spine, Surgery.

Cerebellar hemorrhage occurs mainly due to hypertension [1]. Postoperative cerebellar hemorrhage, on the other hand, is known to be frequently associated with frontotemporal craniotomy [2], but rarely with a spine operation [3]. Minimal cerebellar hemorrhage may be treated with medication and close observation while severe hemorrhage should be corrected surgically.

Postoperative mental depression may occur due to the taking of narcotics for pain control, hypothermia, metabolic disorders such as electrolyte imbalance, or disorders in the central nerve system [4]. These authors report a case of cerebellar hemorrhage after a spine fixation operation for a lower-limb tingling sensation on a 56-year-old female, which was misdiagnosed as a complication of narcotics use.

\section{Case Report}

A 56-year-old female was admitted to these authors' facility for spine fixation due to a two-year continuous lower-limb tingling sensation. She was $153 \mathrm{~cm}$ tall and weighed $38 \mathrm{~kg}$. Other than hysterectomy and chemotherapy ten years earlier, she had no underlying disease. Her PT, aPTT, and platelet count were within the normal range. She thus showed no signs of coagulopathy.

Under noninvasive monitoring, anesthetic induction was carried out with intravenous injection of thiopental $200 \mathrm{mg}$ and rocuronium $30 \mathrm{mg}$, after which intubation was done. The anesthesia was maintained with remifentanil $0.05-0.1 \mu \mathrm{g} / \mathrm{kg} /$ min and sevoflurane $1-2$ vol\%.

Received: July 23, 2010. Revised: September 17, 2010. Accepted: September 30, 2010.

Corresponding author: Hyun Kyoung Lim, M.D., Department of Anesthesiology and Pain Medicine, Inha University Hospital, Inha University College of Medicine, 7-206, Sinheung-dong 3-ga, Jung-gu, Incheon 400-711, Korea. Tel: 82-32-890-3968, Fax: 82-32-881-2476, E-mail: hkliman@inha.ac.kr (c) This is an open-access article distributed under the terms of the Creative Commons Attribution Non-Commercial License (http:// creativecommons.org/licenses/by-nc/3.0/), which permits unrestricted non-commercial use, distribution, and reproduction in any medium, provided the original work is properly cited. 
Spine fusion of the third and fourth lumbar spine was done in the prone position, during which the systolic blood pressure, heart rate, percutaneous oxygen saturation, and end-expiratory carbon dioxide partial pressure were maintained at 100-120 $\mathrm{mmHg}, 60-90,100 \%$, and $33-37 \mathrm{mmHg}$, respectively. Her ABGA with $\mathrm{FiO}_{2}$ at 0.5 (oxygen + room air) was $\mathrm{pH}$ 7.48, $\mathrm{PCO}_{2}$ $38 \mathrm{mmHg}, \mathrm{PO}_{2} 294 \mathrm{mmHg}$, and $\mathrm{HCO}_{3} 25.3 \mathrm{mmol} / \mathrm{L}$, while her electrolytes were $\mathrm{Na} 137, \mathrm{~K} 3.1$, and $\mathrm{Cl} 0.91 \mathrm{mEq} / \mathrm{L}$.

The overall operation time was five hours. The estimated blood loss was $800 \mathrm{ml}$, and the patient was given $400 \mathrm{ml} \mathrm{RBC}$ transfusion, 2,200 ml crystalloid, and $500 \mathrm{ml}$ colloid.

When the operation was finished, a patient-controlled analgesic device was added to her IV line. This device continuously infused $0.5 \mathrm{ml}$ drug per hour, and when she needed more, $0.5 \mathrm{ml}$ was infused every 15 minutes. The device contained 1,000 $\mu \mathrm{g}$ fentanyl and $8 \mathrm{mg}$ ondansetron, where normal saline was added, totaling $60 \mathrm{ml}$. Overall, the device could infuse 9-45 $\mu \mathrm{g}$ fentanyl per hour.

After the operation, the patient showed no specific neurologic deficit. She was transferred to the recovery room under the supervision of an anesthesiologist, where she stayed for 30 minutes, after which she was transferred to the general ward, without any neurologic deficit.

Seventeen hours after the operation, the patient complained of nausea, which was controlled with intravenous metoclopramide $10 \mathrm{mg}$, which is known to be effective against nausea after narcotics use. Nineteen hours after the operation, the patient was still nauseous and lethargic, which were thought to be complications of narcotics use. Thus, the PCA was stopped. Until then, however, about $600 \mu \mathrm{g}$ fentanyl had been administered to the patient. Twenty-one hours after

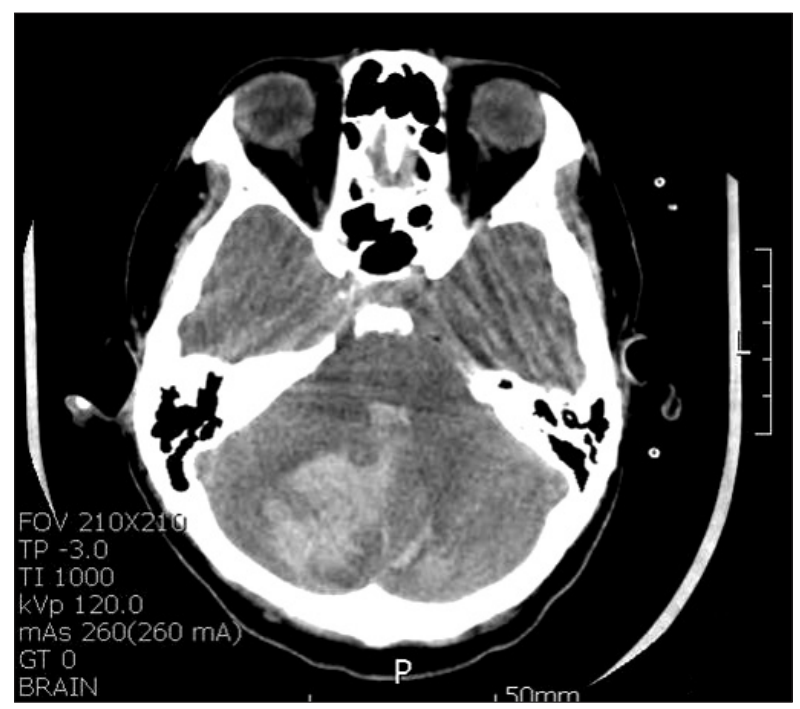

Fig. 1. Brain computed tomographic image shows cerebellar hemorrhage within vermis. the operation, the patient was disoriented and unresponsive to voices, so computed tomography of her brain was taken, which showed cerebellar hemorrhage (Fig. 1). Angio CT did not demonstrate any malformation, such as aneurysm or arteriovenous malformation.

Emergent decompressive craniotomy was carried out to remove the hematoma. Then the patient was moved to the surgical intensive care unit. The intracranial pressure was 0-1 mmHg. As the patient showed no improvement in terms of lethargy, tracheostomy was performed after ten days. Although her consciousness level returned to alert 30 days after the operation, she still suffered ataxia and aphasia. She was transferred to the rehabilitation department, where her symptoms improved. She was then transferred to another hospital for conservative management.

\section{Discussion}

Cerebellar hemorrhage after craniotomy or a spine operation was first reported by Chadduck [5], and there have been few reports of it since then. Despite the many opinions regarding it, there are no definitely proven causes of cerebellar hemorrhage from a spine operation. Hypertension, bleeding tendency, and undiscovered cerebral aneurysm may be some of the causes.

According to Chadduck [5], increased blood pressure increased the gap between the intravascular pressure and the cerebrospinal-fluid pressure, which caused the hemorrhage in the case he presented. Andrews and Koci [6] reported that the hemorrhage in the case they presented was due to reperfusion after temporary traction, entanglement, and spasm of the superior cerebellar artery. Some authors suggested that the position during an operation is related with cerebellar hemorrhage, which may happen particularly when the patient is in a sitting position or when the head is overextended, compressing the jugular veins [7]. In the case presented herein, however, there was no blood pressure increase, and the patient was in a supine position, without vein compression.

Honegger et al. [8] discovered cerebellar hemorrhage via brain CT scan in a patient who received subgaleal suction drainage and who had no specific symptoms, suggesting that extensive suction drainage may cause hemorrhage.

Brockmann et al. [9] reported a unique cerebellar hemorrhagic pattern shown in CT after an operation, assuming cerebrospinal-fluid leakage as the most plausible explanation. Friedman et al. [10] mentioned cerebellar hemorrhage occurring from the temporary compression of the superior cerebellar artery caused by the downward migration of the cerebellum after cerebrospinal-fluid leakage.

Suction drainage was performed in the case presented herein; $890 \mathrm{ml}$ body fluid was drained on the first day, which 
was stopped when the patient showed neurologic symptoms. Considering that the drained fluid was serosanginous, cerebrospinal-fluid leakage cannot be ruled out, which coincides with Friedman et al.'s mention [10] of cerebellar migration and hemorrhage.

Cerebrospinal-fluid leakage indicates dura mater tearing. Kuslich et al. [11] reported dura mater tearing in $3-10 \%$ of the cases after spinal fixation, while Chen et al. [12] reported 3.4\%. Scintigraphy is the definite diagnostic method for dura mater tearing, which was not taken in the case presented herein. Thus, cerebrospinal-fluid leakage due to dura mater tearing could not be confirmed.

Nowadays, postoperative pain control is often performed with the use of patient-controlled analgesic devices. Narcotics use may result in respiratory depression, nausea and vomiting, urinary difficulty, pruritus, and sedation [13]. Although sedation rarely occurs, as neurological signs can be overlooked, narcotics use is usually avoided when neurological evaluation is required after surgery. Dolin and Cashman [13] reported that $25.2 \%$ of the patients in his study suffered from nausea, and $20.2 \%$ from vomiting, after the use of narcotics. Dolin and Cashman [13] also reported mild sedation after intravenous patient-controlled analgesic device use in $56.5 \%$ of the patients, and severe sedation in $5.3 \%$. Ready et al. [14] suggested that severe sedation may be an early symptom of respiratory depression. The symptoms in this case were also misinterpreted as side effects of patient-controlled analgesic device. When postoperative patients become lethargic, various causes should be considered, such as cerebellar hemorrhage in the case presented herein.

Brockmann and Groden [4] reported that symptoms were apparent within 10 hours in $46 \%$ of postoperative cerebellarhemorrhage cases, 10-20 hours in 17\%, 20-30 hours in $17 \%$, $30-40$ hours in $3 \%$, and after 40 hours in $17 \%$. In the case presented herein, the symptoms were manifested 17 hours after the operation.

In the case presented herein, the patient, who did not manifest any specific problem from the surgery or anesthesia, showed nausea and lethargy the day after the operation, regarded as complications of fentanyl administration. Despite the discontinuation of fentanyl administration, however, her symptoms were aggravated. Cerebellar hemorrhage was eventually diagnosed via emergency CT scan.

When a patient's consciousness, respiration, and muscle tone recover fully from anesthesia and lethargy develops, or when there is no improvement of the lethargy after discontinuing the narcotics use, other problems besides the side effects of narcotics use should be considered, which may cause neurological deficit. Cerebellar hemorrhage after a spine operation may be rare, but it should always be considered for prompt diagnosis and treatment, to prevent severe neurologic complications.

\section{References}

1. Ott KH, Kase CS, Ojemann RG, Mohr JP. Cerebellar hemorrhage: diagnosis and treatment. A review of 56 cases. Arch Neurol 1974; 31: 160-7.

2. König A, Laas R, Herrmann HD. Cerebellar haemorrhage as a complication after supratentorial craniotomy. Acta Neurochir (Wien) 1987; 88: 104-8.

3. Konya D, Ozgen S, Pamir MN. Cerebellar hemorrhage after spinal surgery: case report and review of the literature. Eur Spine J 2006; 15: 95-9.

4. Brockmann MA, Groden C. Remote cerebellar hemorrhage: a review. Cerebellum 2006; 5: 64-8.

5. Chadduck WM. Cerebellar hemorrhage complicating cervical laminectomy. Neurosurgery 1981; 9: 185-9.

6. Andrews RT, Koci TM. Cerebellar herniation and infarction as a complication of an occult postoperative lumbar dural defect. AJNR Am J Neuroradiol 1995; 16: 1312-5.

7. Thomas G, Jayaram H, Cudlip S, Powell M. Supratentorial and infratentorial intraparenchymal hemorrhage secondary to intracranial CSF hypotension following spinal surgery. Spine (Phila Pa 1976) 2002; 27: E410-2.

8. Honegger J, Zentner J, Spreer J, Carmona H, Schulze-Bonhage A. Cerebellar hemorrhage arising postoperatively as a complication of supratentorial surgery: a retrospective study. J Neurosurg 2002; 96 : 248-54.

9. Brockmann MA, Nowak G, Reusche E, Russlies M, Petersen D. Zebra sign: cerebellar bleeding pattern characteristic of cerebrospinal fluid loss. Case report. J Neurosurg 2005; 102: 115962.

10. Friedman JA, Ecker RD, Piepgras DG, Duke DA. Cerebellar hemorrhage after spinal surgery: report of two cases and literature review. Neurosurgery 2002; 50: 1361-3.

11. Kuslich SD, Ulstrom CL, Griffith SL, Ahern JW, Dowdle JD. The Bagby and Kuslich method of lumbar interbody fusion. History, techniques, and 2-year follow-up results of a United States prospective, multicenter trial. Spine (Phila Pa 1976) 1998; 23: 1267-78.

12. Chen L, Tang T, Yang H. Complications associated with posterior lumbar interbody fusion using Bagby and Kuslich method for treatment of spondylolisthesis. Chin Med J 2003; 116: 99-103.

13. Dolin SJ, Cashman JN. Tolerability of acute postoperative pain management: nausea, vomiting, sedation, pruritus, and urinary retention. Evidence from published data. Br J Anaesth 2005; 95: 584-91.

14. Ready LB, Oden R, Chadwick HS, Benedetti C, Rooke GA, Caplan R, et al. Development of an anesthesiology-based postoperative pain management service. Anesthesiology 1988; 68: 100-6. 